\title{
DA DEFINIÇÃO DA ESCRAVIDÃO DE ACORDO COM A CORTE INTERAMERICANA DE DIREITOS HUMANOS À LUZ DO CASO TRABALHADORES DA FAZENDA BRASIL VERDE Vs. BRASIL
}

\author{
Francisco José Rocha Pereira* \\ Rodrigo Rocha Gomes de Loiola*
}

RESUMO: Objetiva-se neste artigo, analisar a sentença da Corte Interamericana de Direitos Humanos (CtIDH) que se debruçou sobre o assunto ao tratar do caso Trabalhadores da Fazenda Brasil Verde vs. Brasil. Tem-se, como pergunta de pesquisa, a seguinte: o que a CtIDH entende como escravidão? Foram adotadas abordagens variadas de pesquisa qualitativa, a partir de revisão bibliográfica disponível sobre o tema. Conclui-se que a escravidão é forma de exploração que rouba a dignidade do trabalhador, muitas vezes mediante o cerceamento da liberdade.

Palavras-chave: Trabalho. Escravidão. Dignidade. Ilegalidade.

\section{ON THE DEFINITION OF SLAVERY ACCORDING TO THE INTER-AMERICAN COURT OF HUMAN RIGHTS IN LIGHT OF THE CASE OF THE HACIENDA BRASIL VERDE WORKERS V. BRAZIL}

\begin{abstract}
This paper aims to analyze the judgment of the Inter-American Juridical Committee that studied over the subject when ruling the case of Hacienda Brasil Verde Workers v. Brasil. The research question is the following: what the Inter-American Human Rights Court (CtIDH) understands as slavery. It was adopted various qualitative research approaches, beginning from a bibliographical review about the subject. It was concluded that slavery is a form of exploration that robs the worker from its dignity, many times with the restriction of their liberty.
\end{abstract}

Keywords: Labor. Slavery. Dignity. Unlawfulness.

\section{INTRODUÇÃO}

\footnotetext{
* Mestre em Direito Internacional pela Universidade Católica de Santos (UNISANTOS). Especialista em Direito Processual (Civil, Penal e Trabalhista) pela Faculdade Maurício de Nassau de Recife (PE). Graduado em Direito pela Universidade Federal de Campina Grande (UFCG). Analista Judiciário, Área Judiciária, do Tribunal Regional do Trabalho da 13ạ Região - PB. 7ạ Vara do Trabalho de Campina Grande-PB. Email: franzepereira@hotmail.com.

* Mestre em Direito Internacional pela Universidade Católica de Santos (UNISANTOS). Especialista em Direito e Processo do Trabalho pela Universidade de Fortaleza. Graduado em Direito pela Universidade Federal do Ceará (UFC). Email: rodrigorochagomes@gmail.com.
} 
O trabalho escravo é secular e sempre foi um problema global, que ao longo dos anos vem sendo combatido ferozmente por institutos e organismos internacionais ligados aos direitos humanos, principalmente após a Primeira Guerra Mundial, com a criação da Organização Internacional do Trabalho (OIT), em 1919.

Inúmeras são as nomenclaturas atribuídas ao que se pode chamar de fenômeno de exploração ilícita e precária do trabalho, que também pode ser denominado de trabalho forçado, trabalho escravo, exploração do trabalho, semiescravidão, trabalho degradante, entre outros, e tais denominações são utilizadas indistintamente para tratar da mesma realidade jurídica.

Dados do ano de 2016 da OIT estimam que mais de 40 milhões de pessoas no mundo foram vítimas da escravidão moderna naquele ano. No Brasil, segundo dados do Observatório Digital do Trabalho Escravo, órgão de monitoramento criado pelo Ministério Público do Trabalho em parceria com a OIT, estima-se que de 2003 a 2018, foram libertados 44.229 trabalhadores que estavam em situação análoga à escravidão (MINISTÉRIO PÚBLICO DO TRABALHO, 2017). É nesse contexto que se insere o objeto deste estudo, na medida em que se propõe a analisar decisão da Corte Interamericana de Direitos Humanos (CtIDH) datada de 20 de outubro de 2016 onde se julgou o Caso dos Trabalhadores da Fazenda Brasil Verde vs. Brasil.

O caso se referia à suposta prática de trabalho forçado e servidão por dívidas na Fazenda Brasil Verde, localizada no Estado do Pará, fatos estes que se enquadravam em um contexto, à época, no qual milhares de trabalhadores eram submetidos anualmente a trabalho escravo. Fundamenta-se a decisão, dentre outras provas, em depoimentos de trabalhadores que conseguiram fugir da Fazenda em questão e que declararam a existência de ameaças de morte caso abandonassem a fazenda, o impedimento de saírem livremente, a falta de salário ou a existência de um salário ínfimo, o endividamento com o fazendeiro, a falta de moradia, alimentação e saúde dignas.

Além disso, imputou-se ao Estado Brasileiro suposta responsabilidade sobre esta situação por ter conhecimento da existência destas práticas em geral e não teria adotado as medidas razoáveis de prevenção e resposta, nem fornecido às supostas vítimas um mecanismo judicial efetivo para a proteção de seus direitos, a punição dos responsáveis e a obtenção de uma reparação. 
Por fim, alega-se a responsabilidade internacional do Estado pelo desaparecimento de dois adolescentes que haviam sido cooptados a trabalhar na Fazenda Brasil Verde, o qual foi denunciado a autoridades estatais sem que, supostamente, houvessem sido adotadas medidas efetivas para determinar o seu paradeiro.

Nesse contexto, busca-se compreender o conceito de trabalho escravo, partindo do estudo da importância do princípio da dignidade da pessoa humana, passando pela conceituação de trabalho escravo e finalizando com a análise do caso em si.

Assim, tem-se como pergunta de pesquisa a seguinte: o que a CtIDH entende como escravidão? A hipótese a ser testada é a de que a escravidão moderna é uma forma de labor que desrespeita a dignidade humana por não oferecer as mínimas condições de trabalho tendo, ainda, como característica, muitas das vezes, a privação da liberdade do trabalhador.

Para tanto, em virtude da temática proposta na pesquisa se constituir como fenômeno multifacetado e amplo, composto de aspectos diversificados, foram adotadas abordagens variadas de pesquisa, aplicando métodos específicos, conforme o tipo de informação a ser encontrada ou fonte de pesquisa a ser trabalhada, mediante pesquisa qualitativa, a partir de uma revisão bibliográfica (livros, periódicos, jornais, revistas, trabalhos acadêmicos, normas nacionais e internacionais pertinentes à matéria, decisões judiciais e demais fontes sobre o assunto) de parte da literatura jurídica disponível sobre o tema, bem como pesquisa quantitativa, e, primordialmente, a ANÁLISE DA SENTENÇA DA CORTE INTERAMERICANA NO Caso dos Trabalhadores da Fazenda Brasil Verde vs. Brasil.

\section{DA DEFINIÇÃo DA ESCRAVIDÃo DE ACORDO COM A CORTE INTERAMERICANA DE DIREITOS HUMANOS À LUZ DO CASO TRABALHADORES DA FAZENDA BRASIL VERDE Vs. BRASIL}

\section{O PRINCÍPIO DA DIGNIDADE DA PESSOA HUMANA E O TRABALHO ESCRAVO}

A dignidade do trabalhador e a busca do trabalho descente são questões que ocupam o debate nacional e internacional, pondo-se como ponto relevante para todo e qualquer pensamento jurídico que se pretenda sério. Nessa seara, o Brasil, apesar de signatário de diversos tratados internacionais que disciplinam o tema, e tratar expressamente em sua Carta 
Magna a dignidade da pessoa humana como preceito fundamental, ainda traz, entre seus domínios, o atraso do trabalho análogo à escravidão (KERSTING; PUHL, 2009).

Década após década, esse tipo de trabalho foi evoluindo em sua formatação, deixando para trás aquele modelo de escravidão tradicional, em que os indivíduos nascem dentro de famílias escravas e continuam nessa condição até o fim de suas vidas, com pouca ou nenhuma chance de deixarem a escravidão, para constituir-se em modelo servil que abarca as mais diversas formas de coerção, o que vem sendo chamado de "escravidão moderna" (MERINO, 2006).

Não obstante as diversas denominações, podemos afirmar que qualquer trabalho que não reúna as condições mínimas necessárias para garantir os direitos do trabalhador, seja cerceando sua liberdade, seja menosprezando sua dignidade, ou até mesmo sujeitando-o a condições degradantes, inclusive em relação ao meio ambiente de trabalho, deve ser considerado trabalho em condição análoga à de escravo (LYRA, 2014).

O princípio da dignidade da pessoa humana sempre foi tema de grande relevância para os estudiosos do assunto. A palavra princípio tem vários sentidos e, usualmente significa começo, o início de tudo, a causa primária. Neste sentido Espíndola (2001, p. 53) comenta que:

Pode-se concluir que a ideia de princípio ou sua conceituação, seja lá qual for o campo do saber que se tenha em mente, designa a estruturação de um sistema de ideias, pensamentos ou normas por uma ideia mestra, por um pensamento chave, por uma baliza normativa, donde todas as demais ideias, pensamentos ou normas derivam, se reconduzem e/ou se subordinam (ESPÍNDOLA, 2001, p. 53).

Em se tratando de normatividade, qualquer norma que venha surgir em um ordenamento jurídico, não pode se contrapor ao princípio antes reconhecido para aquele tema, e o Princípio da Dignidade da Pessoa Humana é reconhecido pela Constituição Brasileira. Assim sendo, normas secundárias não podem se contrapor a esse princípio.

A palavra dignidade acompanha o homem desde sua essência, quando se agregou a outros temas para sobreviverem às intemperes da vida. A dignidade da pessoa humana é tema corrente na sociedade, em qualquer que seja a época analisada, por abranger diversos valores comuns a qualquer sociedade. A dignidade da pessoa humana é conceituada por diversos estudiosos, porém, Sarlet (2007, p. 62) tem o seguinte magistério sobre o assunto: 
[...] temos por dignidade da pessoa humana a qualidade intrínseca e distintiva de cada ser humano que o faz merecedor do mesmo respeito e consideração por parte do Estado e da comunidade, implicando, neste sentido, um complexo de direitos e deveres fundamentais que asseguram a pessoa tanto contra todo e qualquer ato de cunho degradante e desumano, como venham a lhe garantir as condições existenciais mínimas para uma vida saudável, além de propiciar e promover sua participação ativa e corresponsável nos destinos da própria existência e da vida em comunhão com os demais seres humanos (SARLET, 2007, p. 62).

Tem-se por esses fundamentos que dignidade é atributo intrínseco, da essência da pessoa humana, único ser que compreende o valor interno, superior a qualquer preço, que não admite substituição equivalente. Assim a dignidade entranha e se confunde com a própria natureza do ser humano, por isso a necessidade da constitucionalização do princípio da dignidade da pessoa humana, que se torna símbolo supremo da democracia.

A Constituição Federal do Brasil, promulgada em 1988, como mencionado acima, colaciona o Princípio da Dignidade da Pessoa Humana em seu artigo primeiro, dentre um dos fundamentos do Estado Democrático de Direito:

Art. $1^{\text {o }}$ A República Federativa do Brasil, formada pela união indissolúvel dos Estados e Municípios e do Distrito Federal, constitui-se em Estado Democrático de Direito e tem como fundamentos:

$[\ldots]$

III - a dignidade da pessoa humana [...].

(BRASIL, 1988).

É por ferir gravemente esse princípio que o trabalho escravo ou, "modernamente", análogo à escravidão torna-se um tema tão importante, pois a escravidão é tão antiga quanto a história do homem e qualquer consideração sobre o trabalho escravo é sempre árdua por envolver diversos aspectos, conforme Melo (2005, p. 218-219):

[...] Com efeito, é necessário entender que 'a categoria trabalho não se circunscreve ao processo de produção e organização do trabalho dentro dos muros e paredes da empresa, mas se estende para fora, invade e modela a vida do trabalhador e suas relações com seus familiares, amigos e vizinhos'. A sua compreensão, portanto, vai além da dimensão exclusivamente socioeconômica, para alcançar os importantes aspectos social, moral e humano, o que incompreensivelmente não encontra guarida em certas formas de trabalho contemporâneo que se restringem a uma fria relação homem-máquina. [...] 
Finalmente é preciso compreender que o trabalho é meio de se ganhar a vida, e não de se perdê-la e, que, o ser humano, é o valor mais importante. Ele é o sujeito-fim de qualquer atividade ou ato humano [...]. (MELO, 2005, p. 218-219).

Ainda é recorrente a ideia do estereótipo que surge no imaginário da maioria das pessoas, no qual o trabalho escravo é ilustrado pelo trabalhador acorrentado, morando na senzala, açoitado e ameaçado constantemente, quando na verdade, o trabalho em condição análoga à de escravo não se caracteriza apenas por aquelas características, mas também pelas más condições de trabalho impostas ao trabalhador, ampliando a abrangência de seu conceito.

O conceito de trabalho forçado esteve presente desde 1930 nos debates da Organização Internacional do Trabalho, em especial, na convenção de $n^{\circ} 29$, que teve sua ratificação no Brasil no ano de 1957. Este documento define o trabalho forçado como "todo trabalho ou serviço exigido de uma pessoa sob a ameaça de sanção e para qual ela não tiver se oferecido espontaneamente". A convenção de no 105 (de 1957) também corrobora essa definição e teve sua ratificação no Brasil em 1965 (OIT, 2011, p. 25-26). De acordo com essas convenções, o trabalho forçado não pode ser equiparado a baixos salários ou más condições de trabalho. Ele inclui uma situação em que os trabalhadores perdem a liberdade. Nesse sentido, nessa concepção, o elemento mais forte se refere à anulação da vontade do trabalhador (BARROSO e PESSANHA, 2018).

Referida Organização Internacional do Trabalho (OIT) acompanha e monitora, mundialmente, as diversas formas de prática do trabalho escravo. A principal característica do trabalho escravo, segundo a OIT, é a falta de liberdade, cujas formas mais comuns de cerceamento são: servidão por dívida, retenção de documentos, dificuldade de acesso ao local e presença de guardas armados. Essas características, frequentemente acompanhadas de condições precárias de vida e de trabalho, são um absoluto desrespeito à dignidade de uma pessoa. Segundo Girardi (et al, 2014, p. 4):

[...] as origens e as formas do cerceamento de liberdade dos trabalhadores são diversas, indo desde o isolamento geográfico até comportamentos ameaçadores dos empregadores. Elas envolvem, grosso modo, aspectos ligados ao local, transporte e alimentação. O trabalho ocorre em locais de difícil acesso, cujo custo de transporte normalmente é caro e debitado aos trabalhadores; a intermediação entre o trabalhador e o empregador é feita por pessoas inescrupulosas, conhecidas como "gato"; a alimentação, comprada em armazéns dos proprietários das fazendas a preços elevadíssimos, transforma-se em dívidas crescentes, as quais se acumulam com o pagamento da viagem e dos instrumentos de trabalho e proteção, que 
deveriam ser fornecidos pelo patrão. As atividades desenvolvidas pelos trabalhadores escravizados são árduas, geralmente associadas às condições degradantes, visto que geralmente os trabalhadores moram em barracos ou em alojamentos comunitários, cujas condições de higiene são as piores possíveis [...] (GIRARDI et al, 2014, p. 4).

A maioria dos trabalhadores libertados estão, predominantemente, nas zonas rurais e ligados às atividades agropecuárias, situação do caso em análise, vez que os trabalhadores, recrutados de diversas partes do país, foram prestar serviços numa fazenda de grande porte no interior do Estado do Pará. Contudo, o crime também é cometido nas áreas urbanas relacionado, principalmente, às atividades de confecção e construção civil.

Exemplificativamente, o Artigo 149 do Código Penal vigente tipifica penalmente o trabalho em condição análoga à de escravo diante de quatro condutas específicas, quais sejam, a a) sujeição da vítima a trabalhos forçados; b) sujeição da vítima a jornada exaustiva; c) sujeição da vítima a condições degradantes de trabalho; d) restrição, por qualquer meio, da locomoção da vítima em razão de dívida contraída com o empregador ou preposto (BRASIL, 1940). Cada um dos modos de execução, embora sejam caracterizados de maneira distinta, pode ser verificado na realidade das relações de trabalho combinados entre si.

Dito isso, é de se fazer uma análise do caso Fazenda Brasil Verde Vs. Brasil, a fim de se estudar os elementos trazidos pela CtIDH para reconhecer o trabalho escravo e, mais ainda, responsabilizar o Estado Brasileiro.

O CASO TRABALHADORES DA FAZENDA BRASIL VERDE Vs. BRASIL E SUA CONCEITUAÇÃO DO TRABALHO ESCRAVO

Feitas tais considerações, passa-se à análise do caso Trabalhadores da Fazenda Brasil Verde Vs. Brasil.

Segundo sentença da CtIDH (2016), a Fazenda Brasil Verde, de propriedade, na época dos fatos, de João Luis Quagliato Neto, fica localizada no município de Sapucaia, no Pará, tendo uma área total de 8.544 hectares e sendo utilizada para a criação de gado.

Ocorre que, nos meses de dezembro de 1988 e janeiro de 1989 a Comissão Pastoral da Terra e a Diocese de Conceição de Araguaia, acompanhados de familiares de Iron Canuto 
da Silva e Luis Ferreira da Cruz, ambos menores, se direcionaram à Polícia Federal a fim de denunciar que seus parentes haviam sido vítimas da prática de trabalho escravo. É que tais trabalhadores foram arregimentados para o exercício profissional em tal fazenda. Ao tentarem abandonar esta, foram ameaçados e, posteriormente, desapareceram. No mesmo dia um trabalhador que havia conseguido escapar narrou que os "peões" que desejassem sair de em paz precisavam fugir, caso contrário, sofriam ameaças de agressão ou mesmo de morte ${ }^{1}$.

Segundo a sentença da $\mathrm{CtIDH}^{2}$ a Polícia Federal chegou a visitar o local, em 20 de fevereiro de 1989, não tendo encontrado vestígios de trabalho escravo. Entretanto, após entrevistas feitas com 51 trabalhadores, constatou-se os baixos salários e diversas infrações à legislação trabalhista. Observou-se, ainda, que os trabalhadores comumente fugiam em razão das dívidas contraídas para com a fazenda.

Cumpre salientar que houve diversas diligências ao longo dos anos em citada fazenda, sem qualquer punição aos responsáveis pela exploração dos trabalhadores. Em verdade, as autoridades, em quase todas as oportunidades, informaram não ter achado pessoas reduzidas à condição análoga à de escravo ${ }^{3}$.

No ano de 1997, as pessoas de José da Costa Oliveira e José Ferreira dos Santos prestaram depoimento frente à sede da Polícia Federal em Marabá/PA, afirmando que, ao aportarem na fazenda para trabalhar já se achavam devedores de valores relativos à hospedagem e utensílios de trabalho. Além disso, informaram que recebiam ameaça de morte caso denunciassem o arregimentador, que a sentença chama pelo adágio popular de gato (ROCHA, 2016), bem como se tentassem fugir. Não bastasse isso, informaram que era prática comum os trabalhadores serem escondidos quando ocorria qualquer fiscalização por parte do Ministério do Trabalho (CtIDH, 2016).

Baseado nesta denúncia:

o Grupo Móvel do Ministério do Trabalho realizou uma nova visita de fiscalização à Fazenda Brasil Verde nos dias 23, 28 e 29 de abril de 1997. O relatório da visita de fiscalização do Ministério do Trabalho concluiu que: i) os trabalhadores se encontravam alojados em barracões cobertos de plástico e palha nos quais havia uma "total falta de higiene"; ii) vários trabalhadores eram portadores de doenças de pele,

\footnotetext{
${ }^{1}$ Op. Cit.

${ }^{2}$ Op. Cit.

${ }^{3}$ Op. Cit.
} 
não recebiam atenção médica e a água que ingeriam não era apta para o consumo humano; iii) todos os trabalhadores haviam sofrido ameaças, inclusive com armas de fogo, e iv) declararam não poder sair da Fazenda. Além disso, comprovou a prática de esconder trabalhadores quando se realizam as fiscalizações. No momento da fiscalização foram encontradas 81 pessoas. "Aproximadamente 45" dessas 81 pessoas não possuíam carteiras de trabalho (CTPS) e tiveram esse documento emitido naquele momento. (CtIDH, 2016, p. 36).

Em razão do relatório do Ministério do Trabalho o Ministério Público Federal apresentou denúncia contra Raimundo Alves da Rocha, gato, Antônio Alves Vieira, gerente da fazenda, e João Luiz Quagliato Neto, proprietário desta ${ }^{4}$. Duarte (2017) ressalta que, no caso deste último, houve a suspensão condicional do processo prevista no art. 89 da lei $\mathrm{n}^{\circ}$ 9.099/95 (BRASIL, 1995) e que, em 2002, o processo foi extinto. Semelhante destino sofreu o processo contra os outros dois denunciados, ocorrendo o arquivamento, desta vez, pela prescrição (CtIDH, 2016).

Já no ano de 1997, a Procuradoria Regional do Trabalho (PRT) da 22a Região, responsável pelo estado do Piaú, informou à PRT da 8 a Região, competente pelo estado do Pará, que a fazenda Brasil Verde estaria cooptando irregularmente trabalhadores daquela região. Em razão disso houve nova fiscalização, dessa vez realizada pela então Delegacia Regional do Trabalho ${ }^{5}$, a qual encontrou algumas irregularidades, tais como cobrança pelos calçados dos trabalhadores e falta de elementos referentes à segurança e higiene no trabalho. Entretanto, preferiu simplesmente orientar os fazendeiros a sanar tais vícios ${ }^{6}$.

A sentença da CtIDH (2016) ainda cita caso ocorrido no ano de 2000, onde o gato conhecido como Meladinho aliciou trabalhadores no município de Barras, PI, com promessa de pagamento de $\mathrm{R} \$ 10,00$ por alqueire ${ }^{7}$ roçado.

Em verdade o pagamento estava longe disso. Já no transporte percebeu-se que tudo não passava de vãs promessas. Os trabalhadores foram transportados em ônibus, trens, os quais não tinham acentos, e caminhões de transporte de animais. Já os alojamentos contavam apenas com telhado de lona. $\mathrm{O}$ banheiro era ao ar livre. Os alimentos eram preparados

\footnotetext{
${ }^{4}$ Op. Cit.

${ }^{5}$ Atualmente o órgão se chama Superintendência Regional do Trabalho e Emprego.

${ }^{6}$ Op. Cit.

${ }^{7} 2,72$ hectares.
} 
também ao ar livre, em quantidade insuficiente e, ao serem fornecidos, logo eram anotados em caderneta para se realizar o desconto do salário ${ }^{8}$.

Ademais, em razão de realizarem os seus trabalhos sob chuva e com os pés encharcados, os trabalhadores comumente adquiriam doenças. Os responsáveis pelas fazendas compravam os medicamentos na cidade e descontavam as importâncias do que era devido a cada trabalhador. Como o pagamento ocorria por produção, os obreiros tinham que trabalhar, mesmo doentes. Não bastasse isso, somente recebiam salários se atingissem uma meta de produção, a qual era bastante difícil de ser alcançada, razão pela qual não recebiam pagamento algum por seus serviços ${ }^{9}$.

Em verdade, conforme se constatou em 2000, os trabalhadores sofriam grave cerceamento do seu direito de ir e vir, chegando a ser ameaçados pelos capatazes, os quais portavam armas de fogo e frequentemente comentavam já terem assassinado um obreiro em uma discussão, tendo este sido enterrado na própria fazenda ${ }^{10}$.

Em citado ano dois trabalhadores conseguiram fugir, direcionando-se a Marabá, PA, onde denunciaram a situação em que viviam. Em razão disso, houve mais uma fiscalização do Ministério do Trabalho, a qual realizou-se em 15 de março de 2000, mas libertou os trabalhadores apenas no dia seguinte. Desta forma os obreiros tiveram que dormir na fazenda fiscalizada, temendo pela própria vida ${ }^{11}$.

A piorar a situação, as autoridades policiais apenas entregaram aos trabalhadores suas carteiras de trabalho e algum dinheiro, sem qualquer explicação. Ocorre que se tratava de pessoas analfabetas, de sorte que não sabiam os documentos que estavam recebendo e nem a que se devia os recursos financeiros ${ }^{12}$.

Essa foi a situação fática posta perante a CtIDH.

De fato, a convenção americana de direitos humanos ao falar sobre o trabalho escravo assim aduz:

\footnotetext{
${ }^{8}$ Op. Cit.

${ }^{9}$ Op. Cit.

${ }^{10}$ Op. Cit.

${ }^{11}$ Op. Cit.

12 Op. Cit.
} 
Artigo 6. Proibição da escravidão e da servidão

1. Ninguém pode ser submetido a escravidão ou a servidão, e tanto estas como o tráfico de escravos e o tráfico de mulheres são proibidos em todas as suas formas.

2. Ninguém deve ser constrangido a executar trabalho forçado ou obrigatório. Nos países em que se prescreve, para certos delitos, pena privativa da liberdade acompanhada de trabalhos forçados, esta disposição não pode ser interpretada no sentido de que pró́be o cumprimento da dita pena, imposta por juiz ou tribunal competente. O trabalho forçado não deve afetar a dignidade nem a capacidade física e intelectual do recluso.

3. Não constituem trabalhos forçados ou obrigatórios para os efeitos deste artigo:

a. os trabalhos ou serviços normalmente exigidos de pessoa reclusa em cumprimento de sentença ou resolução formal expedida pela autoridade judiciária competente. Tais trabalhos ou serviços devem ser executados sob a vigilância e controle das autoridades públicas, e os indivíduos que os executarem não devem ser postos à disposição de particulares, companhias ou pessoas jurídicas de caráter privado;

b. o serviço militar e, nos países onde se admite a isenção por motivos de consciência, o serviço nacional que a lei estabelecer em lugar daquele;

c. o serviço imposto em casos de perigo ou calamidade que ameace a existência ou o bem-estar da comunidade; e

d. o trabalho ou serviço que faça parte das obrigações cívicas normais.

(OEA, 1969)

É de se dizer, a escravidão é, em qualquer situação, afastada pelo Direito Internacional, o qual se ocupa inclusive em dizer em quais situações não ocorre tal fenômeno.

Ora, hodiernamente não é tão comum a escravidão legalmente prevista nos ordenamentos jurídicos como em tempos outros. Em razão disso a convenção sobre a escravatura, de 1926, se preocupou em trazer ao conceito a escravidão por dívidas, ocorrente de fato, não de direito, como a que ocorreu no caso em comento.

Nota-se que os trabalhadores da fazenda Brasil Verde estavam submetidos a uma relação laboral por tempo indeterminado em que assumiam dívidas constantes para com o empregador, as quais não conseguiam saldar ou sequer diminuir.

Não bastasse isso, viviam no interior dos locais onde trabalhavam, tendo seus movimentos cuidadosamente monitorados pelos capatazes, que exerciam controle psicológico e físico sobre os obreiros, os quais não conseguiam modificar sua condição.

Ademais, os trabalhadores eram tratados de forma abusiva e cruel, não podendo serem atendidos por médicos, verem seus familiares ou mesmo fazer suas necessidades fisiológicas com a privacidade que tais atos requerem. 
Moura e Diehl (2017) relembram que esses requisitos, conforme trazidos na sentença ora comentada, advém, em verdade, da Convenção de 1926, com alterações trazidas pela Convenção Suplementar de 1956. É bem verdade que tais requisitos não estão expressamente previstos na Convenção Americana de Direitos Humanos, mas, como falado na própria sentença em comento, um tratado internacional é algo vivo e deve ser interpretado de forma atualizadora e dentro do sistema de proteção em que se insere (CtIDH, 2016).

Tal conclusão da Corte é de uma importância ímpar. É que a própria defesa do Estado Brasileiro argumentou que somente se pode considerar escravidão aquela em que ocorre o exercício de propriedade ou quaisquer de seus efeitos de uma pessoa sobre outra (DUARTE, 2017). Em outras palavras, o Brasil buscava que se aplicasse ao caso apenas a conceituação trazida pela Convenção da OIT de 1926, coincidente com o que consta da Convenção Americana de Direitos Humanos.

A sentença analisada traz, ainda, conceitos sobre trabalho escravo, conforme fora definido pela Comissão Interamericana de Direitos Humanos:

A Comissão afirmou que o Direito Internacional proíbe a escravidão, a servidão, o
trabalho forçado e outras práticas análogas à escravidão. A proibição da escravidão e
de práticas similares forma parte do Direito Internacional consuetudinário e do jus
cogens. A proteção contra a escravidão é uma obrigação erga omnes e de
cumprimento obrigatório por parte dos Estados, a qual emana das normas
internacionais de direitos humanos. A proibição absoluta e inderrogável de
submissão de pessoas a escravidão, servidão ou trabalho forçado está também
estabelecida na Convenção Americana e em outros instrumentos internacionais dos
quais o Brasil é parte. A Comissão realizou precisões a respeito dos conceitos
mencionados anteriormente. Em primeiro lugar, afirmou que a escravidão, de acordo
com a Convenção sobre a Escravatura de 1926 (doravante denominada a
"Convenção de 1926 "), deve ser entendida como o exercício dos atributos do direito
de propriedade sobre uma pessoa. Em segundo lugar, afirmou que o conceito
contemporâneo de escravidão inclui a servidão por dívidas como uma prática
análoga à escravidão e, portanto, também proibida pela Convenção Americana. Os
elementos da servidão por dívidas seriam: i) a prestação de serviços como garantia
de uma dívida que, no entanto, não diminui com esses pagamentos; ii) a falta de
limites à duração dos serviços; iii) a falta de definição da natureza dos serviços; iv)
que as pessoas vivam na propriedade onde prestam os serviços; v) o controle sobre
os movimentos das pessoas; vi) a existência de medidas para impedir as fugas; vii) o
controle psicológico sobre as pessoas; viii) as vítimas não podem modificar sua
condição, e ix) a existência de tratamentos cruéis e abusivos (CtIDH, 2016, p. 56).

$\mathrm{Na}$ análise meritório, a CtIDH (2016), aplicando conceitos trazidos pelo Tribunal Penal Internacional Ad Hoc para a antiga Iugoslávia, o Tribunal Especial para Serra Leoa e a Corte de Justiça da Comunidade Econômica da África Ocidental, determinou que, a fim de se 
determinar o exercício do direito de propriedade sobre alguém, deve-se observar se, no caso concreto, ocorreram os seguintes elementos:
a) restrição ou controle da autonomia individual;
b) perda ou restrição da liberdade de movimento de uma pessoa;
c) obtenção de um benefício por parte do perpetrador;
d) ausência de consentimento ou de livre arbítrio da vítima, ou sua impossibilidade ou irrelevância devido à ameaça de uso da violência ou outras formas de coerção, o medo de violência, fraude ou falsas promessas;
e) uso de violência física ou psicológica;
f) posição de vulnerabilidade da vítima;
g) detenção ou cativeiro,
i) exploração.
(CtIDH, 2016, p. 72)

Além disso, a CtIDH (2016) afirmou que, para os fins previstos no art. 6.1 da Convenção Americana de Direitos Humanos, tráfico de escravos e de mulheres se refere ao recrutamento, transporte alojamento ou acolhimento de pessoas mediante recurso à violência ou grave ameaça, ou mesmo outras formas de coação, tais como sequestro, fraude ou abuso de autoridade e com fins de exploração. Ressaltou, ainda, que para o menor de 18 anos, o requisito de ameaça, fraude ou coação não é necessário.

Já a definição de trabalho forçado é no sentido de que será assim considerado todo serviço exigido de alguém sob ameaça e para o qual não se submeteu de livre e espontânea vontade $^{13}$. Especificamente quanto ao último requisito, tal "situação pode ocorrer por distintas causas, tais como a privação ilegal da liberdade, o engano ou a coação psicológica" (CtIDH, 2016, p. 78).

Conforme rememora Duarte (2017), no caso concreto a Corte reconheceu, à partir das provas trazidas aos autos, que houve um verdadeiro sistema de aliciamento de trabalhadores por meios ardilosos, submetendo-os a um regime de escravidão por dívidas, uma vez que, desde o traslado até coisas mais mundanas havia cobrança irregular por parte do empregador, importando em elevados descontos salariais. Não bastasse isso os trabalhadores eram submetidos a jornadas extremamente cansativas, em condições incondizentes com a de

\footnotetext{
${ }^{13}$ Op. Cit.
} 
um ser humano, sob constante ameaça de violência física e psicológica, bem como efetivo controle por parte dos gatos, seguranças e, em última análise, do proprietário da fazenda. Nesse sentido a sentença em comento:

a Corte constata que: i) os trabalhadores se encontravam submetidos ao efetivo controle dos gatos, gerentes, guardas armados da fazenda, e, em última análise, também de seu proprietário; ii) de forma tal que sua autonomia e liberdade individuais estavam restringidas; iii) sem seu livre consentimento; iv) através de ameaças, violência física e psicológica, v) para explorar seu trabalho forçado em condições desumanas. Além disso, as circunstâncias da fuga realizada pelos senhores Antônio Francisco da Silva e Gonçalo Luiz Furtado e os riscos enfrentados até denunciarem o ocorrido à Polícia Federal demonstram: vi) a vulnerabilidade dos trabalhadores e vii) o ambiente de coação existente nesta fazenda, os quais viii) não lhes permitiam alterar sua situação e recuperar sua liberdade. Por todo o exposto, a Corte conclui que a circunstância verificada na Fazenda Brasil Verde em março de 2000 representava uma situação de escravidão.

(CtIDH, 2016, p. 79/80)

Assim, nota-se que a CtIDH, neste que foi o seu primeiro caso relativo à escravidão (DUARTE, 2017), tomou o cuidado de não só trazer os requisitos que considera para configurar uma situação "moderna" de escravidão como também de fazer um distinguish entre esta e a servidão por dívida, menos gravosa.

Portanto, conforme se observa do julgado do caso Trabalhadores da Fazenda Brasil Verde Vs. Brasil, a fim de se caracterizar situação de escravidão, a teor do disposto no artigo $6^{\circ}$ da Convenção Americana de Direitos Humanos, deve ocorrer a restrição ou controle da autonomia individual, perda ou restrição à liberdade de movimento, obtenção de benefício por parte do perpetrador, ausência de consentimento ou de livre arbítrio, ou mesmo sua irrelevância face ao uso de violência ou fraude, o uso de violência física ou psicológica, a posição de vulnerabilidade da vítima, a detenção ou cativeiro e a exploração.

\section{CONSIDERAÇÕES FINAIS}

O princípio da dignidade da pessoa humana evoluiu bastante com o passar dos anos, bem como o próprio conceito de trabalho escravo.

Em um primeiro momento tal instituto achava-se completamente atado a uma condição juridicamente reconhecida. 
Entretanto, com a compreensão do verdadeiro conceito de trabalho escravo, partindo do estudo da importância do princípio da dignidade da pessoa humana, passando pela conceituação de trabalho escravo e finalizando com a análise do caso em si, observa-se que não há mais a necessidade de que, para que se tenha uma atividade escravagista haja uma autorização, ou mesmo uma permissão fática do Estado.

Em verdade a escravidão moderna é uma forma de labor que desrespeita a dignidade humana por não oferecer as mínimas condições de trabalho tendo, ainda, como característica, muitas das vezes, a privação da liberdade do trabalhador.

A CtIDH, de forma coerente com seu papel de salvaguarda continental dos Direitos Humanos, compreendeu, a partir do caso concreto sob análise, que, para se caracterizar situação de escravidão, a teor do disposto no artigo $6^{\circ}$ da Convenção Americana de Direitos Humanos, deve ocorrer a restrição ou controle da autonomia individual, perda ou restrição à liberdade de movimento, obtenção de benefício por parte do perpetrador, ausência de consentimento ou de livre arbítrio, ou mesmo sua irrelevância face ao uso de violência ou fraude, o uso de violência física ou psicológica, a posição de vulnerabilidade da vítima, a detenção ou cativeiro e a exploração.

Estando presentes tais características, de forma contumaz, estar-se-á perante atividade escravagista.

Além do mais, citada Corte ainda deu interpretação atualizadora ao preceito do art. 6.1. da Convenção Americana de Direitos Humanos. É que afirmou que tráfico de escravos e de mulheres se refere, em verdade, ao recrutamento, transporte alojamento ou acolhimento de pessoas mediante recurso à violência ou grave ameaça, ou mesmo outras formas de coação, tais como sequestro, fraude ou abuso de autoridade e com fins de exploração. Ressaltou, ainda, que para o menor de 18 anos, o requisito de ameaça, fraude ou coação não é necessário.

\section{REFERÊNCIAS}

BRASIL. CONSTITUIÇÃo DA REPÚBLICA FEDERATIVA DO BRASIL, de 5 de outubro de 1988. 
BRASIL. Decreto N ${ }^{\circ}$ 2.848, de 7 de dezembro de 1940. CÓDIGO PENAL. Disponível em: http://www.planalto.gov.br/ccivil_03/decreto-lei/Del2848compilado.htm. Acesso em: 27 out. 2019.

BRASIL. Lei $\mathrm{n}^{\circ}$ 9.099, de 26 de setembro de 1995. DISPÕE SOBRE OS JUIZADOS ESPECIAIS CÍVEIS E CRIMINAIS E DÁ OUTRAS PROVIDÊNCIAS. Disponível em: http://www.planalto.gov.br/ccivil 03/LEIS/L9099.htm. Acesso em: 27 out. 2019.

CORTE INTERAMERICANA DE DIREITOS HUMANOS (CtIDH). CASO TRABALHADORES DA FAZENDA BRASIL VERDE VS. BRASIL. Exceções Preliminares, Mérito, Reparações e Custas, Sentença de 20 de outubro de 2016. Washington: [s.n]. 2014.

DUARTE, L. P. J. O CASO FAZENDA BRASIL VERDE: CAPITAL, TRABALHO, DEPENDÊNCIA E DIREITO NO SISTEMA INTERAMERICANO DE DIREITOS HUMANOS, 2017, Dissertação (Mestrado) - Universidade Federal de Santa Catarina, Florianópolis.

ESPÍNDOLA, R. S. CONCEITO DE PRINCÍPIOS CONSTITUCIONAIS. 2. São Paulo: Revista dos Tribunais, 2001.

GIRARDI, E. P. et al. MAPEAMENTO DO TRABALHO ESCRAVO CONTEMPORÂNEO NO BRASIL: DINÂMICAS RECENTES. Espaço e Economia [Online], 2014, disponível em: <http://journals.openedition.org/espacoeconomia/804>. Acesso em 08 out. 2019.

KERSTING, T. P.; PUHL, A. J. TRABALHO ESCRAVO FRENTE OS DIREITOS FUNDAMENTAIS DO TRABALHADOR: PERSPECTIVA DE ERRADICAÇÃO. REVISTA JURÍDICA UNIGRAN. DOURADOS, MS. V.11, N.22, JUL-DEZ 2009. DisPONÍVEL EM: $\langle$ http://www.unigran.br/revista_juridica/ed_anteriores/22/artigos/artigo10.pdf $>$. ACESSO EM: 08 OUT. 2019.

LYRA, A. R. T. O ENFRENTAMENTO DO TRABALHO EM CONDIÇÃO ANÁLOGA À DE ESCRAVO. Revista Estudos Avançados. 28 (81). Ano 2014. Pag. 213-227. DISPONÍVEL

EM:

<http://www.scielo.br/scielo.php?script=sci arttext\&pid=S010340142014000200015>.

ACESSO EM: 08 OUT. 2019.

MELO, R. S. DIGNIDADE DA PESSOA HUMANA E MEIO AMBIENTE DO TRABALHO. REVISTA DiREITO DO TRABALHO. V.31, N. 117, JAN/MAR. 2005. DiSPONÍVEL EM: $<$ http://boletimcientifico.escola.mpu.mp.br/boletins/boletim-cientifico-n.-14-2013-janeiromarco-de-2005/dignidade-humana-e-meio-ambiente-do-trabalho>. ACESSO EM: 08 OUT. 2019.

MERINO, L. T. DIREITOS HUMANOS E DIREITO DO TRABALHO: ENFOQUES HUMANISTAS NA PROTEÇÃO DOS DIREITOS SOCIAIS. DISSERTAÇÃO DE MESTRADO, FD/USP. ANO DE DEFESA 2006.

MINISTÉRIO PÚBLICO DO TRABALHO. OBSERVATÓRIO DIGITAL DO TRABALHO ESCRAVO NO BRASII: 2017. Disponível em: <http://observatorioescravo.mpt.mp.br>. Acesso em 08 out. 2019. 
MOURA, A. S.; DIEHL, R. C. A CONDENAÇÃO DO BRASIL NO CASO TRABALHADORES DA FAZENDA BRASIL VERDE PELA CORTE INTERAMERICANA DE DIREITOS HUMANOS: AS POSSÍVEIS ALTERAÇÕES NAS POLÍTICAS PÚBLICAS DE ERRADICAÇÃO DO TRABALHO ESCRAVO. XIII Seminário Nacional Demandas Sociais e Políticas Públicas na Sociedade CONTEMPORÂNEA. SANTA CRUZ DO SUL, RS, 2017.

ORGANIZAÇÃO DOS ESTADOS AMERICANOS (OEA). CONVENÇÃO AMERICANA SOBRE DIREITOS HUMANOS. 1969. Ratificada pelo Brasil em 1992. DISPONÍVEL EM: $\langle$ http://www.direito.usp.br/pos/pos_stricto_2006_diss_teses_def_dtb_01.php〉 $>$. ACESSO EM 05 OUT. 2019.

ROCHA, C. C. O CASO "TRABALHADORES DA FAZENDA BRASIL VERDE VS. BRASIL": TRAJETÓRIAS DE LUTA POR JUSTIÇA DE TRABALHADORES ESCRAVIZADOS. REVISTA DO ARQUiVo GERAL DA CidADE DO RIO DE JANEIRO. RIO DE JANEIRO, RJ. N.11, 2016.

SARLET, I. W. DIGNIDADE DA PESSOA HUMANA E DIREITOS FUNDAMENTAIS NA CONSTITUIÇÃO FEDERAL DE 1988. 5. ed. Porto Alegre: Livraria do Advogado, 2007.

VERGara, S. $\quad$ C. PROJETOS E RELATórios DE PESQUISA EM ADMINISTRAÇÃO. 14. ED. SÃo PAULO: ATLAS, 2013. 